\title{
Could perimenopausal oestrogen prevent breast cancer?
}

Isaac Manyonda ${ }^{1}$, Vikram Talaulikar ${ }^{2}$, Roxanna Pirhadi ${ }^{3}$, Dibyesh Banerjee ${ }^{1}$, and Joseph Onwude ${ }^{4}$

${ }^{1}$ St George's University Hospitals NHS Foundation Trust

${ }^{2}$ University College London Hospitals NHS Foundation Trust

${ }^{3}$ Anglia Ruskin University

${ }^{4}$ The Chelmsford Private Day Surgery Hospital

October 20, 2020

\begin{abstract}
Breast cancer is the commonest cancer among women in the western world, accounting for up to $30 \%$ of all cancers in women. There is a long-standing controversy about the potential link to hormone replacement therapy (HRT), with large observational studies suggesting that HRT increases the risk, while the Women's Health Initiative (WHI), a prospective, randomised placebocontrolled trial has reported several times over a period of 20 years that combined (oestrogen and progestogen) HRT increases the risk, while oestrogen-only HRT given to women who have had a prior hysterectomy, is associated with a significantly reduced risk of developing breast cancer.
\end{abstract}

\section{Hosted file}

Could perimenopausal Estrogens Prevent Breast Cancer.pdf available at https://authorea.com/ users/368690/articles/487750-could-perimenopausal-oestrogen-prevent-breast-cancer

\section{Hosted file}

Figure 1.pdf available at https://authorea.com/users/368690/articles/487750-couldperimenopausal-oestrogen-prevent-breast-cancer 